\title{
Derivation of pluripotent, embryonic cell lines from the pig and sheep
}

\author{
Elena Notarianni*, C. Galli†, S. Laurie†, R. M. Moor† and M. J. Evans* \\ * Department of Genetics, University of Cambridge, Downing Street, Cambridge CB2 3EH, UK, \\ and $\uparrow$ Institute of Animal Physiology \& Genetics Research, Department of Molecular Embryology. \\ Babraham, Cambridge CB2 4AT, UK
}

\begin{abstract}
Summary. As previously described for the establishment of stable, pluripotent cell lines from pig blastocysts, an analogous cell line was isolated from a sheep blastocyst. There are common features in the morphologies and growth characteristics of the pig and sheep cells in culture; in particular, pig and sheep cells display large nuclei and relatively sparse cytoplasm, as is observed in mouse embryonic stem cells. Furthermore, the morphology of the sheep cells closely resembles that of cells in primary cultures of inner cell masses isolated immunosurgically from sheep blastocysts. This suggests that the sheep cell line represents a primary ectodermal lineage.
\end{abstract}

Keywords: embryonic stem cells; pig; sheep; tissue culture

\section{Introduction}

The technologies for the derivation and experimental utilization of embryonic stem (ES) cells from the mouse are well established (Evans \& Kaufman, 1981; Martin, 1981). To extend these technologies from the mouse to the major domestic species would be of considerable experimental and practical interest. However, consideration of two specific differences in the development of murine and ungulate embryos suggests that the methods devised for the mouse system may not be directly applicable to the ungulates (Notarianni et al., 1990). Firstly, the isolation of mouse ES cells may have been facilitated by the timing of differentiation of the blastocysts, in that the inner cell mass cells may be isolated from hatched blastocysts at Day 3.5 , before the onset of delamination of primary endoderm (which occurs on Day 4), as co-culture leads to rapid disappearance of pluripotential stem cells (Robertson, 1987). Although an analogous situation pertains in the blastocyst of the pig (in that the embryonic disc delaminates an inner layer of embryonic endoderm between 10 and 12 days, i.e. after the time at which we explant our blastocysts into culture), it is not possible to obtain inner cell masses from hatched sheep blastocysts that are free from endodermal contamination. In sheep, the blastocyst is fully expanded and hatches at 7 days, when the delamination of endoderm has already occurred (Handyside et al., 1987). One particular problem which might beset derivation of sheep cells is to obtain a population of stem cells not yet influenced by differentiated products. To this end, we attempted to isolate sheep embryonic cell lines not only by explanting whole embryos into culture followed by rapid selection of stem-cell-like colonies, but also by immunosurgical isolation of inner cell masses.

Secondly, development of the inner cell mass differs significantly between murine and ungulate species; in mouse embryos proliferation of the inner cell mass occurs rapidly, whereas in ungulate embryos the inner cell mass forms a mitotically quiescent embryonic disc. This suggests that the growth characteristics and morphology of embryonic stem cells from ungulates may differ from that of mice, and that those of pig and sheep may resemble each other more than those of mice. 


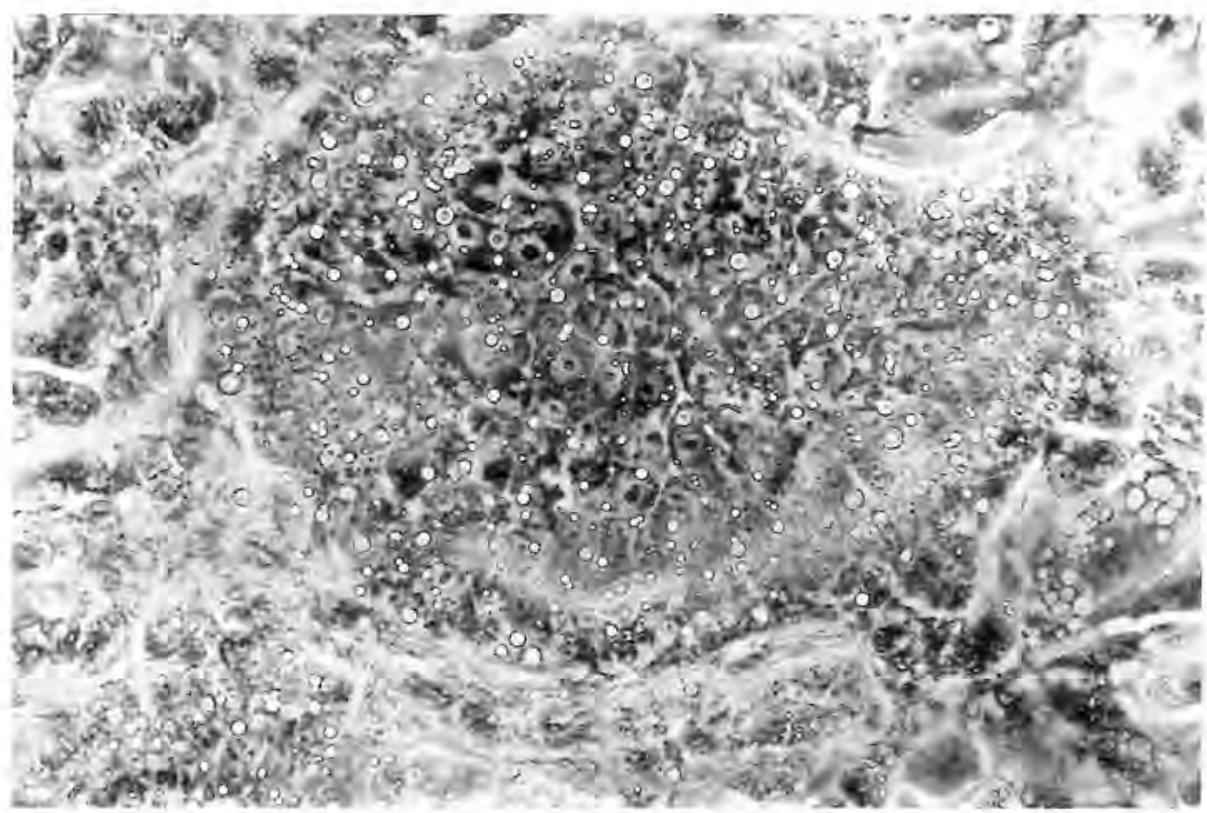

Fig. 1. Colony of pluripotential pig cells cultured on mitotically-inactivated STO fibroblasts. $\times 250$,

\section{Methods}

Conditions for the recovery of pig blastocysts and for the derivation and culture of pluripotential pig cell lines were as described previously (Notarianni et al., 1990).

Welsh Mountain ewes were induced to superovulate by injection with 1200 i.u. PMSG on the 12 th day of the oestrous cycle, and mated with 2 rams at the onset of oestrus (Day 0). Blastocysts, typically 3 or 4 per animal, were collected surgically by retrograde flushing of the uterine horns at 7-9 days after oestrus. The recovered blastocysts (totalling approximately 200) were then either explanted into culture, or subjected to immunosurgery to isolate the inner cell masses. Culture of intact blastocysts or isolated inner cell masses was on mitotically-inactivated STO fibroblasts with Dulbecco's modified Eagle's medium supplemented with $10 \%$ newborn calf serum and $5 \%$ fetal calf serum (both newborn and fetal calf sera were heat-inactivated at $56^{\circ} \mathrm{C}$ for $30 \mathrm{~min}$ ), and $0.1 \mathrm{~mm}-\beta$ mercaptoethanol. Derivative cells from outgrowths of the inner cell masses were isolated by trypsinization using $0.25 \%(\mathrm{w} / \mathrm{v})$ trypsin in $0.04 \%(\mathrm{w} / \mathrm{v})$ EDTA, and passaged onto fresh, inactivated STO cells using the above medium.

Immunosurgical preparation of pure inner cell masses was performed as described by Solter \& Knowles (1975). Antiserum was raised in rabbits by two injections of ovine trophectodermal tissue which was dissected from 14-18-day embryos. This antiserum was incubated at $56^{\circ} \mathrm{C}$ for 30 min to inactivate complement. Blastocysts were first mechanically dissected into inner cell masses, which then were exposed to the rabbit anti-trophectodermal antiserum (1:5 dilution in serum-free medium) for $30 \mathrm{~min}$, washed in complete medium, and exposed to guinea-pig complement (1:10 dilution) for $30 \mathrm{~min}$. Residual, attached endodermal and trophectodermal cells were killed by this procedure, and could be removed by mechanical disaggregation.

\section{Results}

The morphology and growth characteristics of our pig cell lines have been described (Notarianni $e t$ al., 1990). A typical colony and a confluent monolayer of such cells are shown in Figs 1 and 2, 


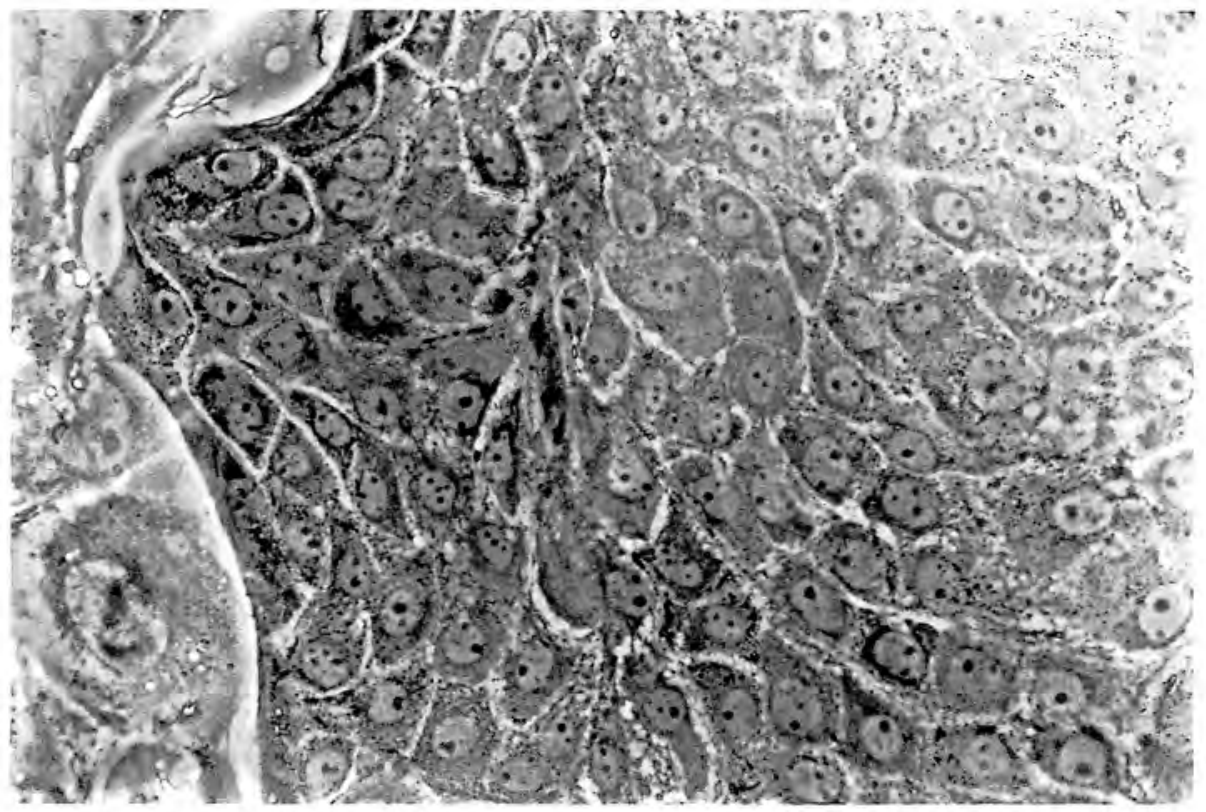

Fig. 2. Confluent monolayer of pig cells. $\times 250$.

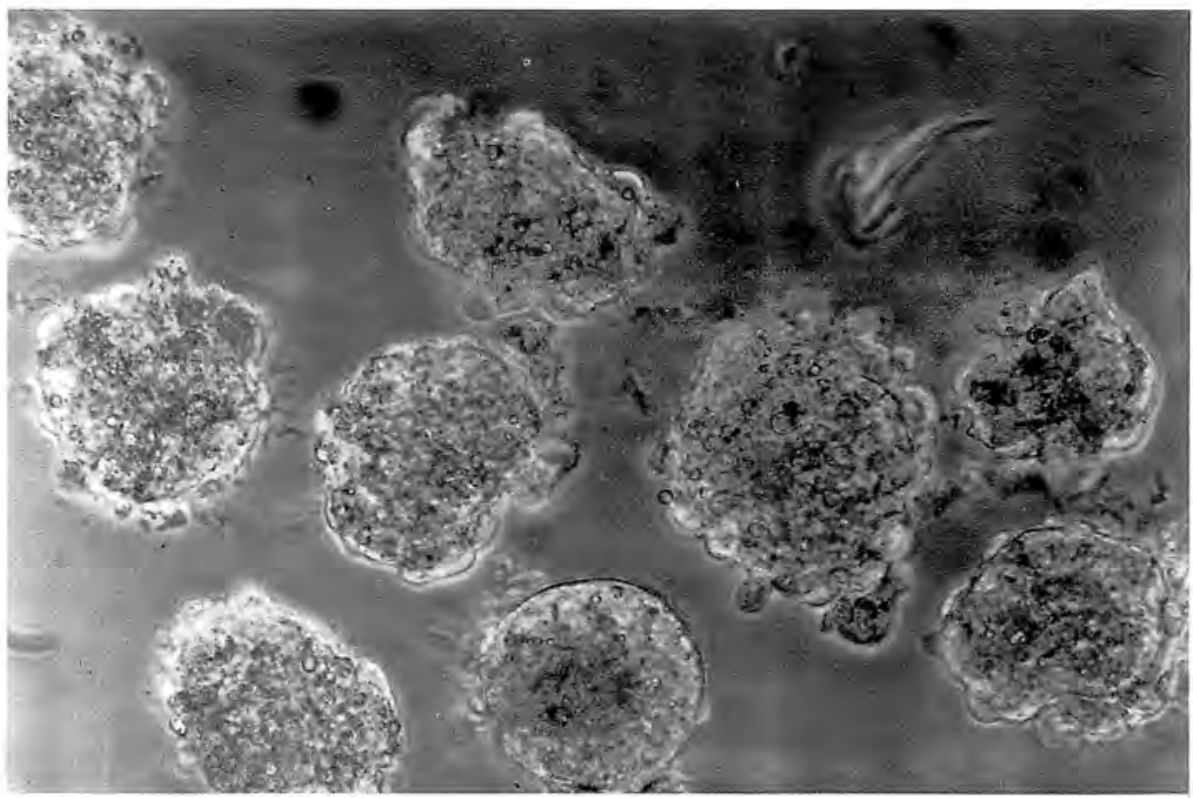

Fig. 3. Sheep inner cell masses prepared by immunosurgery of 8-day blastocysts. $\times 100$.

respectively. Figure 3 shows sheep inner cell masses which were isolated by immunosurgery of blastocysts, and Fig. 4, a single inner cell mass explanted into culture. Outgrowths were isolated more frequently from isolated inner cell masses than from intact blastocysts (at an efficiency of around $80 \%$ for $7-9$-day embryos), but failed to survive more than 2 or 3 passages in culture. Intact 


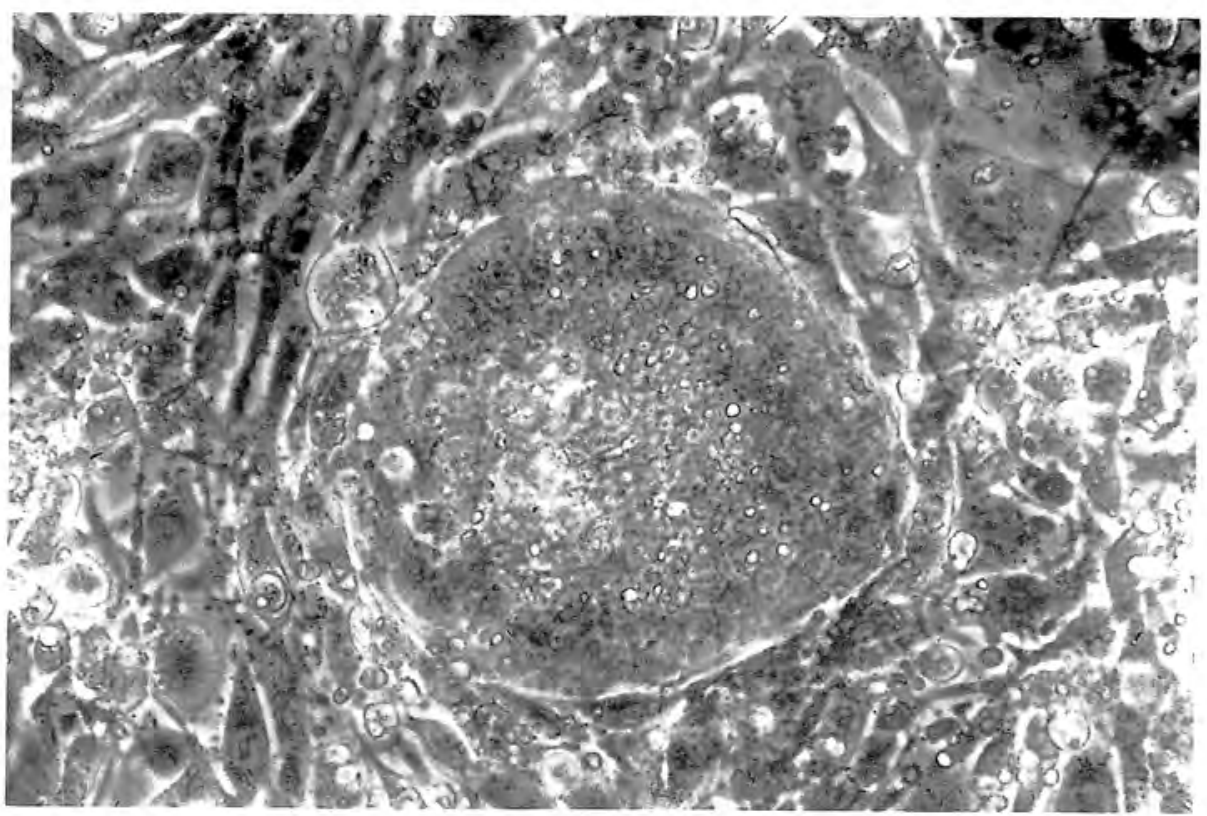

Fig. 4. Sheep inner cell mass after attachment to monolayer of mitotically-inactivated STO cells, after $24 \mathrm{~h}$ in culture. $\times 200$.

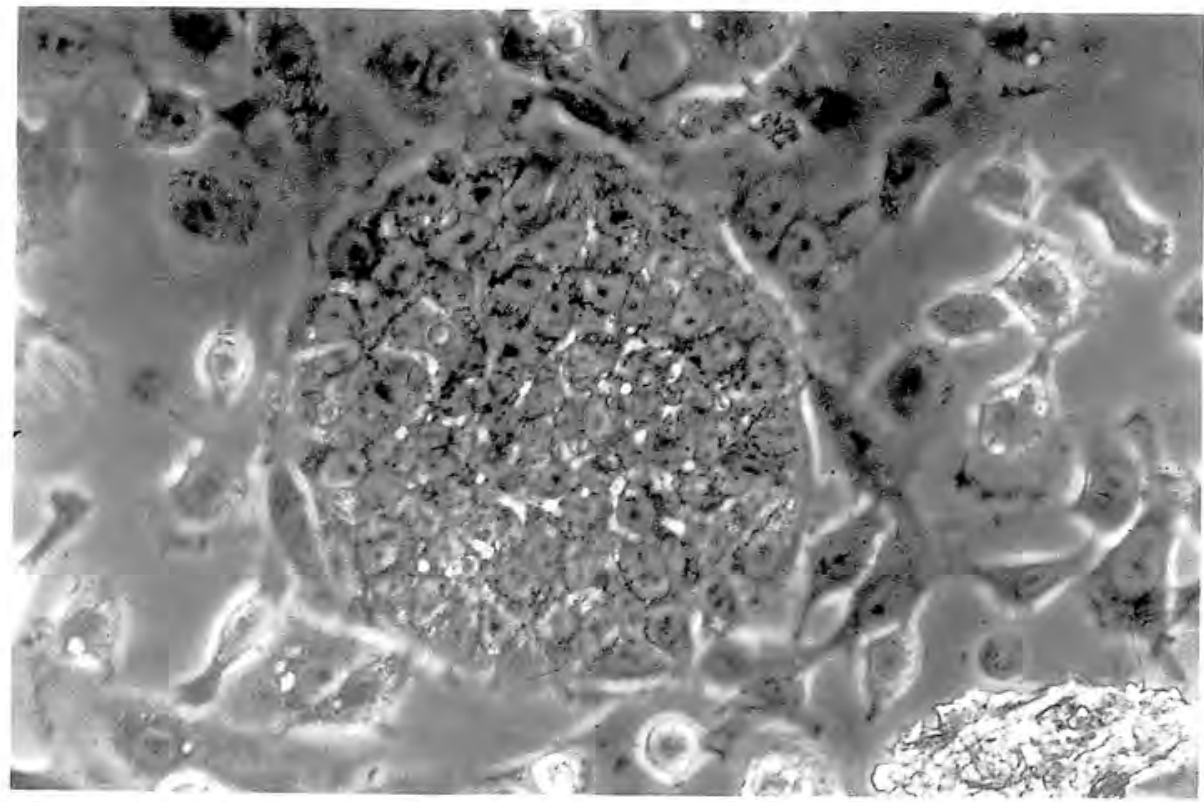

Fig. 5. Colony of cells of the sheep line derived from an intact 8 -day blastocyst. $\times 250$.

embryos were slow or failed to attach to feeder layers in culture, and not all embryos which attached gave rise to outgrowths from the inner cell masses. However, in one particular experiment, 2 hatched, 8-day-old sheep embryos were explanted intact onto fibroblast feeder layers and monitored closely. Primary outgrowths which were recognized as precursors to embryonic stem 


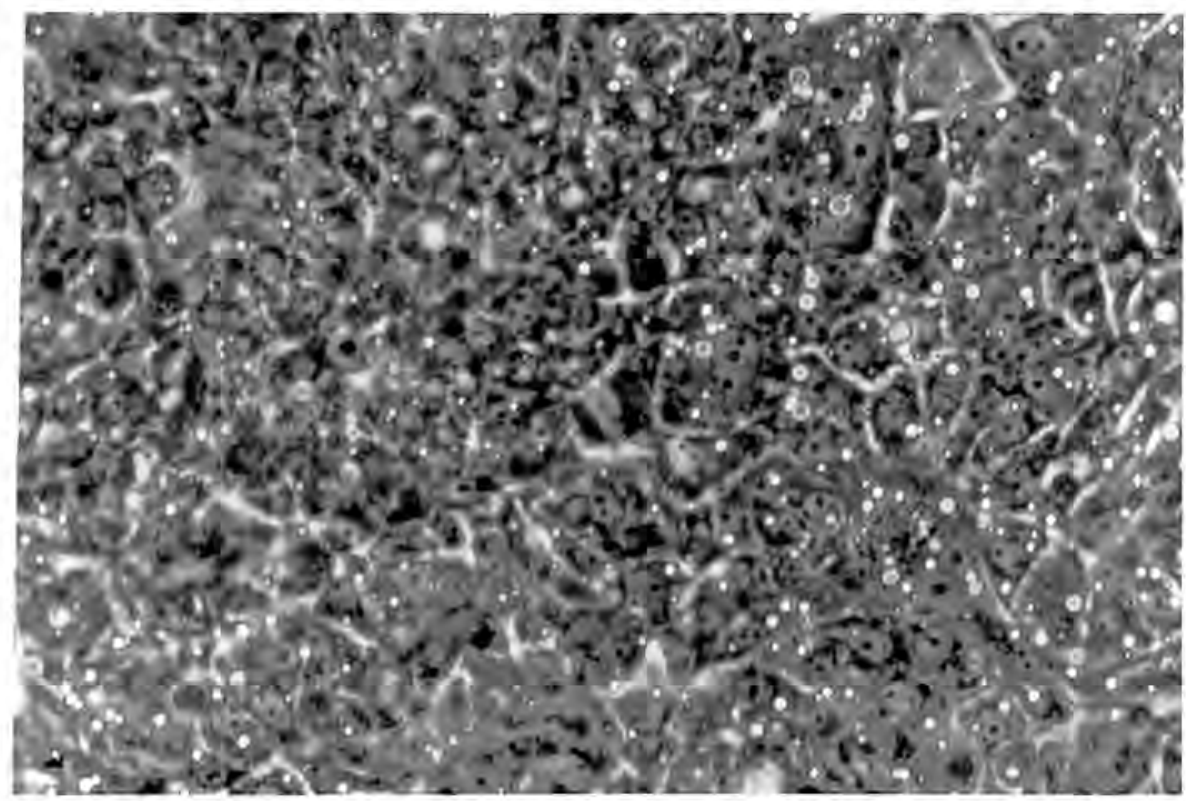

Fig. 6. Culture of the sheep cell line at a high density. $\times 250$.

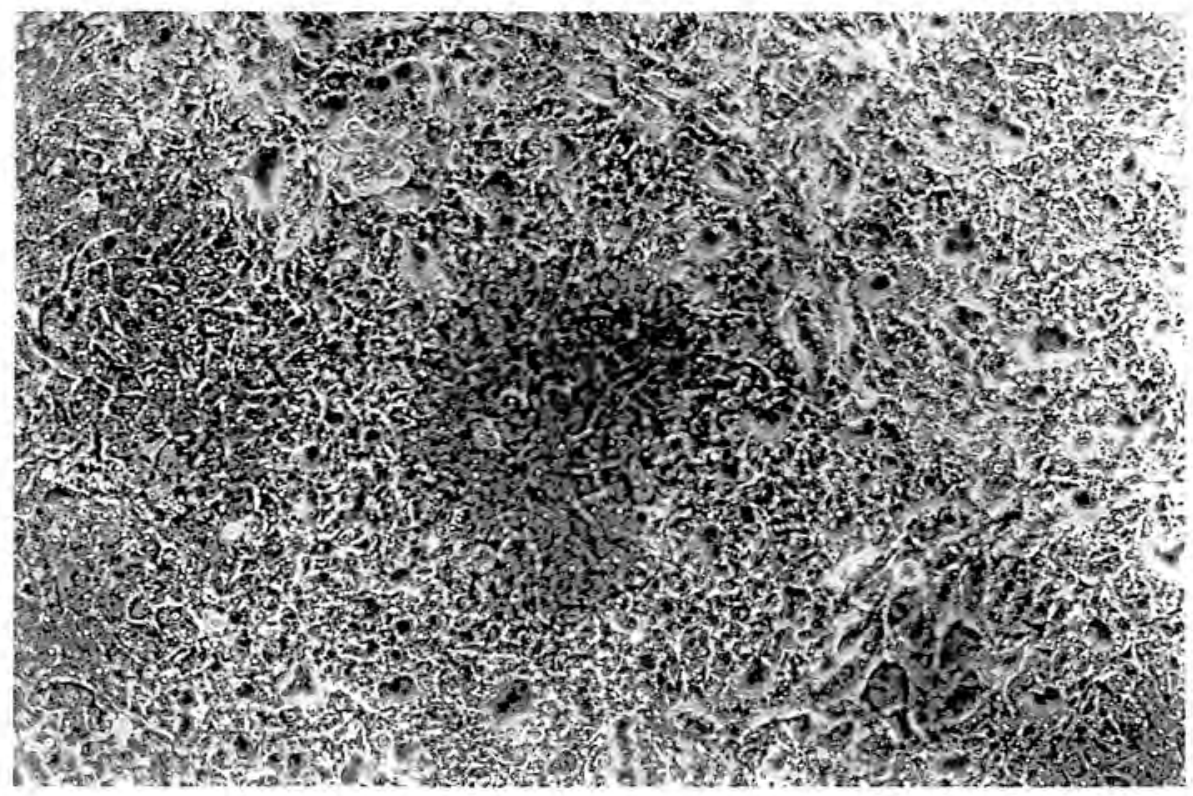

Fig. 7. Sheep cell line showing spontaneous differentiation into cells of various morphologies. $\times 100$.

cells were collected and passaged. After 7 such passages of material from one blastocyst, a culture was derived which was free from trophectodermal material, and became stable to passaging in the undifferentiated state. This culture has formed a cell line, maintaining a stable morphology (Figs 5 \& 6) closely resembling that of inner-cell-mass cells in culture (Fig. 4) as well as that of our pig cell 
lines (Figs 1 \& 2): the cells are epithelial in character, and have a large nuclear to cytoplasmic ratio which is a feature also of mouse ES cells (Evans \& Kaufman, 1981; Martin, 1981). The sheep cells are approximately $25 \mu \mathrm{m}$ in diameter, whereas pig and mouse cells are $35-50 \mu \mathrm{m}$ and $18 \mu \mathrm{m}$, respectively. Like the pig cells, the sheep cells grow in flattened colonies, which eventually spread to form monolayers (Fig. 6). The sheep cells show a rate of growth similar to that of pig cells, and are passaged at 3-day intervals or before attaining confluence: the cells spontaneously differentiate on reaching confluence into a range of morphological types (Fig. 7), including fibroblast-, muscle- and nerve-like derivatives.

\section{Discussion}

The method we have described for the isolation of pluripotential embryonic cells from the pig were successfully applied to isolate a similar sheep cell line, and may serve as a general method for the identification and isolation of embryonic cells from ungulate embryos. This indicates that the identification and isolation of pluripotential, stem-cell-like lines may be similar for different species of ungulates.

Unlike mouse ES cells, our pig and sheep embryonic cells do not show a tendency to form multilayered colonies in our culture conditions, but grow in distinctive epithelioid colonies which spread to form monolayers. Cells in either case have large, clear nuclei, several prominent nucleoli and relatively little cytoplasm. The sheep cells closely resemble cells in primary cultures of inner cell masses, consistent with their having been derived from a primary ectodermal lineage.

Pig and sheep cells demonstrate a slower rate of division than mouse ES cells. This may reflect the formation of a relatively quiescent embryonic disc by the inner cell mass in the ungulate embryo before implantation, compared with the rapid proliferation of cells in the inner cell mass of the mouse embryo at this stage.

Our success in isolating a sheep cell line from an explanted, intact sheep blastocyst may have been due to the timing of collection and passaging of outgrowths from the inner cell mass, so that populations of cells were obtained which were free from the differentiative effects of endoderm cells. Failure to isolate a cell line by the immunosurgical method may have been due to induction of differentiation by the treatments involved. This procedure was noted to induce at least a decrease in the adhesion properties of the cells (unpublished results). We are attempting to improve the isolation conditions in order to prolong the period during which the isolated inner cell masses may be cultured, and are investigating the use of these cells for differentiation and developmental studies in vitro and in vivo.

\section{References}

Evans, M.J. \& Kaufman, M.H. (1981) Establishment in culture of pluripotential cells from mouse embryos. Nature, Lond. 292, $154-156$.

Handyside, A., Hooper, M.L., Kaufman, M.H. \& Wilmut, I. (1987) Towards the isolation of embryonic stem cell lines from the sheep. Roux Arch. 196, 185-197.

Martin, G.R. (1981) Isolation of a pluripotential line from early mouse embryos cultured in medium conditioned by teratocarcinoma stem cells. Proc. natn. Acad. Sci. USA 78, 7634-7638.

Notarianni, E., Laurie, S. Moor, R.M. \& Evans, M.J. (1990) Maintenance and differentiation in culture of pluripotential embryonic cell lines from pig blastocysts. J. Reprod, Fert, Suppl, 41, 51-56,

Robertson, E.J. (1987) Embryo-derived stem cells. In Terarocarcinomas and Embryonic Stem Cells. A Practical Approach, pp. 71-112, Ed, E. J. Robertson. IRL Press, Oxford.

Solter, D. \& Knowles, B.B. (1975) Immunosurgery of mouse blastocysts. Proc natn. Acad. Sci, USA 72, 5099-5102. 